\title{
Multi-Objective Chance Constrained Capacitated Transportation Problem based on Fuzzy Goal Programming
}

\author{
Surapati Pramanik \\ Department of Mathematics, Nandalal Ghosh \\ B.T. College, Panpur, P.O.- Narayanpur, \\ District - North 24 Parganas, Pin Code- \\ 743126, West Bengal, India
}

\author{
Durga Banerjee \\ Ranaghat Yusuf Institution,Rathtala,P.O.- \\ Ranaghat,District-Nadia,Pin Code- \\ 741201,West Bengal, India
}

\begin{abstract}
This paper presents chance constrained multi-objective capacitated transportation problem based on fuzzy goal programming problem. Generally, in transportation problem the capacity of each origin and the demand of each destination are random in nature. The inequality constraints representing supplies and demands are probabilistically described. In many real situations, there are capacity restrictions on units of commodities which are shipped from different sources to different destinations. In the model formulation, supply and demand constraints are converted into equivalent deterministic forms. Then, we define the fuzzy goal levels of the objective functions. The fuzzy objective goals are then characterized by the associated membership functions. In the solution process, two fuzzy goal programming models are considered by minimizing negative deviational variables to obtain compromise solution. Distance function is used in order to obtain the most compromise optimal solution. In order to demonstrate the effectiveness of the proposed approach, an illustrative example of chance constrained multiobjective capacitated transportation problem is solved.
\end{abstract}

\section{General Terms}

Transportation, Optimization

\section{Keywords}

Fuzzy Goal Programming, Chance Constrained Programming, Transportation Problem, Capacitated Transportation Problem, Randomness, Membership function, Multi objective decision making.

\section{INTRODUCTION}

Transportation problem (TP) is one of the most important application of linear programming in the real life situations. TP is mainly used to find out the shipping routes as well as the resourse allocation so that the total transportation cost would be minimum. The classical TP is a linear programming problem with equality constraints. Hitchcock [1] first developed the simpliest TP model in 1941. Koopmans [2] studied TP extensively in the form of activity analysis of production and allocation in 1951. Charnes and Cooper [3] presented the stepping stone method in order to explain linear programming calculation in transportation problem in 1954. Kantorovich[4] studied the mathematical methods of organising and planning production in 1960. Haley [5] proposed the solid TP model with single objective in 1963. Patel and Tripathy[6] discussed the variants of solid TP in 1989. Ringuest and Rinks [7] developed efficient interactive algorithm for solving multiobjective TP. Current and Min [8] designed multi objective TP networks. Appa [9] studied TP and its variants. The concept of Appa was further developed by Brigden[10] with mixed type constraints. Misra and Das [11-12] considered the capacity restrictions in single objective solid TP. Klingman et al.[13] developed the NETGEN theory for generating large scale capacitated assignment transportation cost network problem. Wagner[14] made a note on a class of capacitated transportation problem. Pramanik and Roy [15] studied fuzzy goal programming (FGP) approach to multi objective TP with capacity restrictions.

Dantzig [16,17] developed the stochastic programming. In stochastic programming, the parameters are described by random variables with known distribution. The chance constrained programming (CCP) was introduced by Charnes and Cooper in 1963[18]. In 1988, Hassin and Zemel [19] studied probabilistic analysis of the capacitated tranportation problem. They showed that asymptotic conditions on the supplies and demands assure a feasible solution to the problem.

In 1992, Bit et al. [20] studied the fuzzy programming approach to multi criteria decision making transportation problem. The coefficients in the objective functions and right hand side parameters of the constraints are crisp numbers. In 1994, Bit et al. [21] also developed a fuzzy programming approach to chance constrained multi objective TP. They considered parameters as standard normal, log-normal, uniform random variables.

In the recent past, Pramanik and Roy [22] Pramanik and Dey [23] studied FGP by considering only negative deviational variables in achievement functions. In this paper, the concept of Pramanik and Dey [23] is further extended to chance constrained FGP and its application in solving multi objective capacitated transportation problem (MOCTP).The right hand parameters of the constraints are random variables of known mean and variance. We consider the random variables as normal distribution with given mean and variance and we convert the normal random variables into standard normal random with zero mean, unit variance. To convert the CCP with known confidence level into deterministic constraints, we use standard normal distribution table.

Rest of the paper is organized in the following way: Section 2 describes multi-objective transportation 
problem. Section 3 presents mathematical model of chance constrained multi-objective capacitated transportation problem. Section 4 is devoted to present proposed FGP formulation of chance constrained multiobjective capacitated transportation problem. Section 7 provides the selection of compromise solution using distance function. In Section 6, illustrative numerical example is solved to show the efficiency of the proposed approach. Section 7 presents the concluding remarks. Finally, Section 8 adds necessary references.

\section{MULTI-OBJECTIVE CAPACITATED TRANSPORTATION PROBLEM}

A transportation problem helps us to find out the way in which resources are allocated properly from origins to destinations so that total transportation costs, time, deterioration during transportation etc. would be minimal.

We consider $\mathrm{p}$ sources (origins) $\mathrm{O}_{\mathrm{i}}(\mathrm{i}=1,2, \ldots, \mathrm{p})$ and $\mathrm{q}$ destinations $D_{j}(j=1,2, \ldots, q)$. At each source $O_{i}(i=1$, $2, \ldots, p)$, let $a_{i}$ be the amount of product to be shipped to the $q$ destinations $D_{j}$ in order to satisfy the demand $b$ $(j=1,2, \ldots, q)$ there. In many practical problems, $a_{i}$ and $b_{j}$ cannot be deterministically provided. Here, $a_{i}, b_{j}$ are considered as random variables with known distribution. In addition, there exists a penalty $\mathrm{c}_{\mathrm{ij}}^{\mathrm{k}}$ associated with transporting a unit of product from source $\mathrm{O}_{\mathrm{i}}$ to destination $D_{j}$ for the $k$-th criterion. In general, $c_{i j}^{k}$ denotes the transportation costs, delivery time, damage charges (loss of quality and quantity of transported items), underused capacity, etc. Let $\mathrm{x}_{\mathrm{ij}}$ be the variable that represents the unknown quantity transported from $\mathrm{i}$ th origin to j-th destination. Since, we are interested in capacitated TP, there are limitations on the amount of resources allocated in different cells. Let $r_{i j}$ be the maximum amount of quantity transported from $\mathrm{i}$-th source to $\mathrm{j}$-th destination i.e. $\mathrm{x}_{\mathrm{ij}} \leq \mathrm{r}_{\mathrm{ij}}$. This restriction is called the capacitated restriction on the route $i$ to $j$.

Considering $\mathrm{k}$ penalty criteria, the mathematical model for MOCTP with chance constraints can be written as:

$$
\min Z^{k}=\sum_{i=1}^{p} \sum_{j=1}^{q} c_{i j}^{k} x_{i j}, \quad k=1,2, \ldots, K
$$

subject to

$$
\begin{aligned}
& \operatorname{Prob}\left(\sum_{j=1}^{q} x_{i j} \leq a_{i}\right) \geq 1-\alpha_{i}, i=1,2, \ldots, p \\
& \operatorname{Prob}\left(\sum_{i=1}^{p} x_{i j} \geq b_{j}\right) \geq 1-\beta_{j}, j=1,2, \ldots, q
\end{aligned}
$$

$$
\begin{aligned}
& 0 \leq \mathrm{x}_{\mathrm{ij}} \leq \mathrm{r}_{\mathrm{ij}} \\
& 0<\alpha_{\mathrm{i}}<1,0<\beta_{\mathrm{j}}<1,
\end{aligned}
$$

Here, $\alpha_{i}, \beta_{j}$ are the known confidence levels for the constraints and the TP is unbalanced TP.

\section{MATHEMATICAL MODEL INVOLVING CHANCE CONSTRAINED MOCTP (CCMOCTP)}

In various real life CCMOCTPs, three cases may arise (i) only $a_{i}$ is random (ii) only $b_{j}$ is random (iii) both $a_{i}, b_{j}$ are random. We are interested in developing the model by considering both $a_{i}, b_{j}$ as random. Case (i) and case (ii) are particular cases of case iii). Here, $a_{i}$ and $b_{j}$ follow normal distribution with known mean $\mathrm{E}\left(\mathrm{a}_{\mathrm{i}}\right), \mathrm{E}\left(\mathrm{b}_{\mathrm{j}}\right)$ and variance $\operatorname{var}\left(a_{i}\right), \operatorname{var}\left(b_{j}\right)$ respectively. The chance constraints are converted into equivalent deterministic forms by the prescribed mean, variance and confidence levels. The process is described in subsection 3.1.

\subsection{Construction of Equivalent Deterministic Constraints}

Consider the chance constraints of the form:

$\operatorname{Prob}\left(\sum_{j=1}^{q} x_{i j} \leq a_{i}\right) \geq 1-\alpha_{i}, i=1,2, \ldots, p$

The constraints can be rewritten as:

$$
\begin{aligned}
& \operatorname{Prob}\left(\frac{\sum_{j=1}^{q} x_{i j}-E\left(a_{i}\right)}{\sqrt{\operatorname{var}\left(a_{i}\right)}} \leq \frac{a_{i}-E\left(a_{i}\right)}{\sqrt{\operatorname{var}\left(a_{i}\right)}}\right) \geq 1-\alpha_{i}, i=1,2, \ldots, p \\
& \Rightarrow \alpha_{i} \geq 1-\operatorname{Prob}\left(\frac{\sum_{j=1}^{q} x_{i j}-E\left(a_{i}\right)}{\sqrt{\operatorname{var}\left(a_{i}\right)}} \leq \frac{a_{i}-E\left(a_{i}\right)}{\sqrt{\operatorname{var}\left(a_{i}\right)}}\right) \\
& \Rightarrow \alpha_{i} \geq \operatorname{Prob}\left(\frac{\sum_{j=1}^{q} x_{i j}-E\left(a_{i}\right)}{\sqrt{\operatorname{var}\left(a_{i}\right)}}>\frac{a_{i}-E\left(a_{i}\right)}{\sqrt{\operatorname{var}\left(a_{i}\right)}}\right) \\
& \Rightarrow \Phi^{-1}\left(\alpha_{\mathrm{i}}\right) \geq \frac{\sum_{\mathrm{j}=1}^{\mathrm{q}} \mathrm{x}_{\mathrm{ij}}-\mathrm{E}\left(\mathrm{a}_{\mathrm{i}}\right)}{\sqrt{\operatorname{var}\left(\mathrm{a}_{\mathrm{i}}\right)}} \\
& \Rightarrow \Phi^{-1}\left(\alpha_{i}\right) \sqrt{\operatorname{var}\left(a_{i}\right)} \geq \sum_{j=1}^{q} x_{i j}-E\left(a_{i}\right) \\
& \Rightarrow \sum_{j=1}^{\mathrm{q}} \mathrm{x}_{\mathrm{ij}} \leq \mathrm{E}\left(\mathrm{a}_{\mathrm{i}}\right)+\Phi^{-1}\left(\alpha_{\mathrm{i}}\right) \sqrt{\operatorname{var}\left(\mathrm{a}_{\mathrm{i}}\right)}
\end{aligned}
$$

Here $\Phi($.$) and \Phi^{-1}($.$) represent the distribution function and$ inverse of distribution function of standard normal variable respectively.

Now consider $\operatorname{Prob}\left(\sum_{\mathrm{i}=1}^{\mathrm{p}} \mathrm{x}_{\mathrm{ij}} \geq \mathrm{b}_{\mathrm{j}}\right) \geq 1-\beta_{\mathrm{j}} \quad \mathrm{j}=1,2, \ldots, \mathrm{q}$.

Then, the constraints can be rewritten as:

$$
\operatorname{Prob}\left(\frac{\sum_{\mathrm{i}=1}^{p} x_{i j}-E\left(b_{j}\right)}{\sqrt{\operatorname{var}\left(b_{j}\right)}} \geq \frac{b_{j}-E\left(b_{j}\right)}{\sqrt{\operatorname{var}\left(b_{j}\right)}}\right) \geq 1-\beta_{j} \quad j=12, \ldots, q
$$




$$
\begin{gathered}
\Rightarrow \Phi\left(\frac{\sum_{i=1}^{p} x_{i j}-E\left(b_{j}\right)}{\sqrt{\operatorname{var}\left(b_{j}\right)}}\right) \geq 1-\beta_{j} \\
\Rightarrow 1-\Phi\left(-\frac{\sum_{i=1}^{p} x_{i j}-E\left(b_{j}\right)}{\sqrt{\operatorname{var}\left(b_{j}\right)}}\right) \geq 1-\beta_{j} \\
\Rightarrow \Phi\left(-\frac{\sum_{i=1}^{p} x_{i j}-E\left(b_{j}\right)}{\left.\sqrt{\operatorname{var}\left(b_{j}\right)}\right) \leq \beta_{j}}\right. \\
\Rightarrow \Phi^{-1}\left(\beta_{j}\right) \geq-\frac{\sum_{i=1}^{p} x_{i j}-E\left(b_{j}\right)}{\sqrt{\operatorname{var}\left(b_{j}\right)}} \\
\Rightarrow-\Phi^{-1}\left(\beta_{j}\right) \leq \frac{\sum_{i=1}^{p} x_{i j}-E\left(b_{j}\right)}{\sqrt{\operatorname{var}\left(b_{j}\right)}} \\
\Rightarrow \sum_{i=1}^{p} x_{i j} \geq E\left(b_{j}\right)-\Phi^{-1}\left(\beta_{j}\right) \sqrt{\operatorname{var}\left(b_{j}\right)}
\end{gathered}
$$

Then the model reduces to deterministic multi-objective transportation problem as follows:

$$
\begin{aligned}
& \min Z^{k}=\sum_{i=1 j=1}^{p} \sum_{i j}^{q} c_{i j}^{k} x_{i j}, k=1,2, \ldots, K \\
& \text { subject to } \sum_{j=1}^{q} x_{i j} \leq E\left(a_{i}\right)+\Phi^{-1}\left(\alpha_{i}\right) \sqrt{\operatorname{var}\left(a_{i}\right)} \\
& \sum_{i=1}^{p} x_{i j} \geq E\left(b_{j}\right)-\Phi^{-1}\left(\beta_{j}\right) \sqrt{\operatorname{var}\left(b_{j}\right)} \\
& 0 \leq x_{i j} \leq r_{i j} \quad i=1,2, \ldots, p \text { and } j=1,2, \ldots, q
\end{aligned}
$$

\section{FGP FORMULATION OF CCMOCTP}

Generally, the objective function $\mathrm{Z}^{\mathrm{k}}$ represents the TP cost, time, damages during transportation. Our intension is to minimize $Z^{k}$ subject to the system constraints (9), (10) and (11). Let the individual best and worst solution of the objective function subject to system constraints be $\mathrm{Z}_{\mathrm{L}}^{\mathrm{k}}$ and $\mathrm{Z}_{\mathrm{U}}^{\mathrm{k}}$ respectively. The fuzzy goals appear as $\mathrm{Z}^{\mathrm{k}} \lesssim \mathrm{Z}_{\mathrm{L}}^{\mathrm{k}}$. The linear membership function for the fuzzy goal can be written as:

$$
\mu_{k}\left(Z^{k}\right)=\left\{\begin{array}{lc}
1, & \text { if } Z^{k} \leq Z_{L}^{k} \\
\frac{Z_{U}^{k}-Z^{k}}{Z_{U}^{k}-Z_{L}^{k}}, & \text { if } Z_{L}^{k} \leq Z^{k} \leq Z_{U}^{k} \\
0, & \text { if } Z^{k} \geq Z_{U}^{k}
\end{array}, k=1,2, \ldots, K\right.
$$

Here $\left(Z_{U}^{k}-Z_{L}^{k}\right)$ is the tolerance range for the k-th goal.

Using the model studied by Pramanik and Dey [23] membership goal of each membership function can be written as:

$$
\mu_{\mathrm{k}}\left(\mathrm{Z}^{\mathrm{k}}\right)+\mathrm{d}^{-\mathrm{k}}=1 \text {, }
$$

Here $\mathrm{d}^{-\mathrm{k}}$ is the negative deviational variable.

Now, the FGP model for CCMOCTP can be formulated as: Model-Ia):

$\min \mathrm{Z}^{\mathrm{k}}=\sum_{\mathrm{k}=1}^{\mathrm{K}} \mathrm{w}^{\mathrm{k}} \mathrm{d}^{-\mathrm{k}}$

subject to

$1 \geq \mathrm{d}^{-\mathrm{k}} \geq 0$

and the constraints (9),(10),(11) and (13).

Here $w^{k}=1 /\left(Z_{U}^{k}-Z_{L}^{k}\right)$

is the associated weight for the $\mathrm{k}$ - th objective function. Model Ib):

$\min \mathrm{Z}^{\mathrm{k}}=\sum_{\mathrm{k}=1}^{\mathrm{K}} \mathrm{d}^{-\mathrm{k}}$

subject to the constraints

(9), (10), (11), (13) and (15).

Model-II

$\min \lambda$

subject to the constraints $\lambda \geq \mathrm{d}^{-\mathrm{k}}$

and (18).

\section{SELECTION OF COMPROMISE SOLUTION}

In the context of multi-objective decision making, we cannot reach the ideal solution points because of incommensurable objective goals and different conflicting constraints. Decision makers (DMs) try to find out the solution which is closest to the ideal point solution considering all objectives and constraints in the decision making situation. In this connection, several distance functions have been studied $[24,25]$ to find out the satisfactory solutions. Here, we use the distance function of the type $\mathrm{s}^{\mathrm{m}}=\left[\sum_{\mathrm{k}=1}^{\mathrm{K}}\left(1-\mu^{\mathrm{k}}\left(\mathrm{Z}^{\mathrm{k}}\right)\right)^{\mathrm{m}}\right]^{1 / \mathrm{m}}$ for $\mathrm{m}=1,2 ; \mathrm{k}=1,2$, $\ldots, \mathrm{K}$.

$\mu^{\mathrm{k}}\left(Z^{\mathrm{k}}\right)$ is the membership value for the $\mathrm{k}$-th objective function. The solution for which the distance would be the minimum should be taken as the best compromise solution. To identify the FGP model that gives the best satisfactory result, we use the distance function.

\section{ILLUSTRATIVE EXAMPLE}

To demonstrate the potentiality of the proposed FGP models, we consider the following example. Here, we consider three origins and three destinations. The TP cost, time and the damage charges (both quality and quantity damage) during the transportation are represented by three square matrices of order three. The matrices are given bellow:

$$
\begin{array}{cccc} 
& 3 & 4 & 13 \\
\text { Cost matrix: } & 12 & 14 & 7 \\
& 15 & 10 & 8 \\
& & & \\
& 9 & 1 & 3 \\
\text { Time matrix: } & 2 & 4 & 6 \\
& 8 & 12 & 10
\end{array}
$$$$
\begin{array}{lll}
8 & 9 & 11
\end{array}
$$

Damage charge: $\begin{array}{lll}3 & 4 & 7\end{array}$ 
Then the objective functions can be represented by $\min \mathrm{Z}^{1}=$

$\left(3 \mathrm{x}_{11}+4 \mathrm{x}_{12}+13 \mathrm{x}_{13}\right)+\left(12 \mathrm{x}_{21}+14 \mathrm{x}_{22}+7 \mathrm{x}_{23}\right)+\left(15 \mathrm{x}_{31}+10 \mathrm{x}_{32}+8 \mathrm{x}_{33}\right)$

$\min \mathrm{Z}^{2}=$

$\left(9 \mathrm{x}_{11}+\mathrm{x}_{12}+3 \mathrm{x}_{13}\right)+\left(2 \mathrm{x}_{21}+4 \mathrm{x}_{22}+6 \mathrm{x}_{23}\right)+\left(8 \mathrm{x}_{31}+12 \mathrm{x}_{32}+10 \mathrm{x}_{33}\right)$

$\min Z^{3}=\left(8 x_{11}+9 x_{12}+11 x_{13}\right)+\left(3 x_{21}+4 x_{22}+7 x_{23}\right)+\left(2 x_{31}+x_{32}+6 x_{33}\right)$

subject to

$\operatorname{Prob}\left(\sum_{\mathrm{j}=1}^{3} \mathrm{x}_{1 \mathrm{j}} \leq \mathrm{a}_{1}\right) \geq 1-\alpha_{1}$

$\operatorname{Prob}\left(\sum_{\mathrm{j}=1}^{3} \mathrm{x}_{2 \mathrm{j}} \leq \mathrm{a}_{2}\right) \geq 1-\alpha_{2}$

$\operatorname{Prob}\left(\sum_{j=1}^{\mathrm{q}} \mathrm{x}_{3 \mathrm{j}} \leq \mathrm{a}_{3}\right) \geq 1-\alpha_{3}$

$\operatorname{Prob}\left(\sum_{i=1}^{3} x_{i 1} \geq b_{1}\right) \geq 1-\beta_{1}$

$\operatorname{Prob}\left(\sum_{\mathrm{i}=1}^{3} \mathrm{x}_{\mathrm{i} 2} \geq \mathrm{b}_{2}\right) \geq 1-\beta_{2}$

$\operatorname{Prob}\left(\sum_{\mathrm{i}=1}^{3} \mathrm{x}_{\mathrm{i} 3} \geq \mathrm{b}_{3}\right) \geq 1-\beta_{3}$

The capacitated constraints are given below:

$0 \leq \mathrm{x}_{11} \leq 6,0 \leq \mathrm{x}_{12} \leq 7,0 \leq \mathrm{x}_{13} \leq 13,0 \leq \mathrm{x}_{21} \leq 6$

$0 \leq \mathrm{x}_{22} \leq 2,0 \leq \mathrm{x}_{23} \leq 13,0 \leq \mathrm{x}_{31} \leq 4,0 \leq \mathrm{x}_{32} \leq 7$.

$0 \leq \mathrm{x}_{33} \leq 14$.

The mean, variance and the confidence levels are described below:

Table1. Comparison of optimal solutions of the numerical example based on distance functions

\begin{tabular}{|c|c|c|c|c|c|}
\hline Approach & Solution point & Objective values & Membership values & $S^{1}$ & $S^{2}$ \\
\hline $\begin{array}{l}\text { Proposed } \\
\text { model (Ia) }\end{array}$ & $5.7119,7,0,0,0,13.46,0,0.1876,0$ & $\begin{array}{l}141.2317,141.4183,203.10 \\
28 .\end{array}$ & $1,0.5942,0.1640$ & 1.24178 & 0.92927 \\
\hline $\begin{array}{l}\text { Proposed } \\
\text { model }(\mathrm{Ib})\end{array}$ & $\begin{array}{l}0.0619,7,0,5.650,0,13.46,0, \\
0.1876,0 .\end{array}$ & $\begin{array}{ll}192.0817, & 101.8683, \\
174.8528 . & \end{array}$ & $\begin{array}{l}0.5899,0.80154, \\
0.39678\end{array}$ & 1.2117 & 0.7559 \\
\hline $\begin{array}{l}\text { Proposed } \\
\text { model (II) }\end{array}$ & $\begin{array}{l}\text { 1.7151,3.6645,0,3.9968,0,13.4, } \\
0,3.5231,0 .\end{array}$ & $\begin{array}{l}\text { 197.2157,150.1313, } \\
156.4349\end{array}$ & $0.5485,0.5485,0.5485$ & 1.3544 & 0.7819 \\
\hline
\end{tabular}

Note: Considering the distance functions $\mathrm{S}^{1}, \mathrm{~S}^{2}$ the solution given by the model (Ib) is the most satisfactory solution.

\section{CONCLUSION}

This paper presents chance constrained fuzzy goal programming and its application for solving CCMOTP. Two chance constrained FGP models are presented. Distance function is used to obtain the compromise solution. The illustrative example shows that the proposed FGP models offer three different solution set. In general, it cannot be possible to state which FGP model offers better optimal solution. Therefore, it is better to solve the problem by suing the proposed FGP models, and then apply distance function to obtain the most satisfactory solution. Proposed FGP models
$\mathrm{E}\left(\mathrm{a}_{1}\right)=12, \operatorname{var}\left(\mathrm{a}_{1}\right)=9, \alpha_{1}=0.01$

$\mathrm{E}\left(\mathrm{a}_{2}\right)=15$, var $\left(\mathrm{a}_{2}\right)=4, \alpha_{2}=0.02$

$\mathrm{E}\left(\mathrm{a}_{3}\right)=20, \operatorname{var}\left(\mathrm{a}_{3}\right)=7, \alpha_{3}=0.03$

$\mathrm{E}\left(\mathrm{b}_{1}\right)=9, \operatorname{var}\left(\mathrm{b}_{1}\right)=2, \beta_{1}=0.01$

$\mathrm{E}\left(\mathrm{b}_{2}\right)=13$, var $\left(\mathrm{b}_{2}\right)=8, \beta_{2}=0.02$

$\mathrm{E}\left(\mathrm{b}_{3}\right)=21, \operatorname{var}\left(\mathrm{b}_{3}\right)=16, \beta_{3}=0.03$

Using (9), (10) and (31), the chance constraints defined in (24) to (29) can be converted into equivalent deterministic constraints as:

$$
\begin{aligned}
& \sum_{j=1}^{3} x_{1 j} \leq 18.975, \sum_{j=1}^{3} x_{2 j} \leq 19.11, \sum_{j=1}^{3} x_{3 j} \leq 24.987, \\
& \sum_{i=1}^{3} x_{i 1} \geq 5.7119, \sum_{i=1}^{3} x_{i 2} \geq 7.1876 \sum_{i=1}^{3} x_{i 3} \geq 13.46
\end{aligned}
$$

The tolerance ranges for the three objective functions are taken as [141.2317, 265.2392], [64.0092, 254.7742], [101.6461, 223.0061]. Following the proposed FGP models, we obtain the compromise solution (See Table 1) as: $\mathrm{x}_{11}=$ $0.0619, \mathrm{x}_{12}=7, \mathrm{x}_{13}=0, \mathrm{x}_{21}=5.650, \mathrm{x}_{22}=0, \mathrm{x}_{23}=13.46, \mathrm{x}_{31}=$ $0, x_{32}=0.1876, x_{33}=0$.

The obtained values of the membership functions for three objective functions are $0.5899,0.80154,0.39678$ and the obtained values of $\mathrm{Z}^{1}, \mathrm{Z}^{2}, \mathrm{Z}^{3}$ are respectively 192.0817 , 101.8683, 174.8528. The obtained values of distance functions are respectively $S^{1}=1.2117, S^{2}=0.7559$. 


\section{REFERENCES}

[1] Hitchcock, F. L. 1941. Distribution of a product from several sources to numerous localities. Journal of Mathematical Physics 20, 224-230.

[2] Koopmans, T. C. 1951. Activity Analysis of Production and Allocation, Cowels Commission Monograph 13, Wiley, New York.

[3] Charnes, A., and Cooper, W. W. 1954. The stepping stone method for explaining linear programming calculation in transportation problem. Management Science 1, 49-69.

[4] Kantorovitch, L. V. 1960. Mathematical methods in the organization and planning of production. Publication House of the Leningrad State University (in Russian Language), English translation in Management Science 6(4), $366-422$.

[5] Haley, K. B.1963.The solid transportation problem. Operation Research 10, 448-463.

[6] Patel, G., and Tripathy, J.1989. The solid transportation problem and its variants. International Journal of Management and Systems 5, 17-36.

[7] Ringuest, J. L., and Rinks, D. B.1987. Interactive solutions for the linear multi-objective transportation problem. European Journal of Operational Research 32, 96-106.

[8] Current, J., and Min, H. 1986. Multiobjective design of transportation networks: taxonomy and annotation. European Journal of Operational Research 26,187-201.

[9] Appa, G. M. 1973. The transportation problem and its variants. Operations Research Quarterly 24, 79-99.

[10] Brigden,M. E. B.1974. A variant of the transportation problem in which the constraints are of mixed type. Operations Research Quarterly 25, 437-445.

[11] Misra, S., and Das, C. 1981a. Three-dimensional transportation problem with capacity restriction. NZOR 9, 47-58.

[12] Misra, S., and Das, C. 1981b. Solid transportation problem with lower and upper bounds on the rim condition-a note. NZOR 9,137-140.

[13] Klingman,D., Napier,A., and Stu, J.1974.NETGEN: a program for generating large scale capacitated assignment, transportation cost network problems. Management Science 20, 814-821.
[14] Wagner, H. M. 1959. ON a class of capacitated transportation problems. Management Science 5, 304318.

[15] Pramanik, S., and Roy, T. R. 2005. A fuzzy goal programming approach for multi-objective capacitated transportation problem. Tamsui Oxford Journal of Management Sciences 21, 75-88.

[16] Dantzig, G. B. 1955. Linear programming under uncertainty. Management Science 1, 197 - 206.

[17] Dantzig, G. B. and Mandansky, A. 1961. On the solution of two-stage linear programs under uncertainty. In I. J Neyman, editor, Proc. 4th Berkeley symp. Math. Stat. Prob., $165-176$

[18] Charnes, A., and Cooper, W. W. 1963. Deterministic equivalent for optimizing and satisfying under uncertainty. Operational Research 11(1), 18 - 39.

[19] Hassin, R., and Zemel, E.1988. Probabilistic analysis of the capacitated transportation problem. Mathematics of Operation Research 13,80-89.

[20] Bit, A. K., Biswal, M. P. and Alam, S. S. 1992. Fuzzy programming approach to multi-criteria decision making transportation problem. Fuzzy Sets and Systems 50, 135-141.

[21] Bit, A. K., Biswal, M. P. and Alam, S. S.1994.Fuzzy programming approach to chance constrained multiobjective transportation problem. The Journal of Fuzzy Mathematics 2,117-130.

[22] Pramanik, S. and Roy, T. K. 2007. Fuzzy goal programming approach to multilevel programming problems. European Journal of Operational Research 176(2), 1151-1166

[23] Pramanik, S. and Dey, P. P. 2011. Quadratic bi-level programming problem based on fuzzy goal programming approach. International Journal of Software Engineering \& Applications 2(4), 41-59.

[24] Yu, P. L. 1973. A class of solutions for group decision problems. Management Science19, 936-946.

[25] Pramanik, S. and Roy, T. K. 2008. Multiobjective transportation model with fuzzy parameters: a priority based fuzzy goal programming. Journal of Transportation Systems Engineering and Information Technology 8 (3), 40-48. 